presented in Fig. 2. It is apparent from Fig. 2 that groups experiencing two pellets in $G 1$ were performing at a higher level than groups receiving eight pellets. Analysis of variance over the seven blocks of preshift trials indicated that the $G 1$ reward magnitude variable was statistically reliable for both start speeds $(F=18.06, d f=1 / 82$, $p<.01)$ and running speeds $(F=14.60$, $\mathrm{df}=1 / 82, \mathrm{p}<.01$ ). The magnitude of $\mathrm{G} 2$ reward, however, failed to affect either the start measure $(\mathrm{F}<1, \mathrm{df}=1 / 82)$ or the running measure $(F=1.10, \mathrm{df}=1 / 82)$. It was further revealed that the $G 1$ by $G 2$ Reward Magnitude interaction achieved significance at the .10 level for the start speeds $(F=3.20, \mathrm{df}=1 / 82)$ and at the .01 level for the running speeds $(F=7.17$, $\mathrm{df}=1 / 82$ ). Orthogonal comparisons of treatment sums indicated that Group 2-8 ran faster than Group 8.8 for both the start measure $(F=18.26, \mathrm{df}=1 / 82, \mathrm{p}<.01)$ and the running measure $(F=21.09, \mathrm{df}=1 / 82$, $\mathrm{p}<.01$ ). Group $8-2$ was not statistically different from Group 2.2 for either the start measure $(\mathrm{F}=2.94, \mathrm{df}=1 / 82)$ or the running measure $(\mathrm{F}<1, \mathrm{df}=1 / 82)$.

\section{Postshift Phase}

Alley 1. Mean Al start and running speeds over blocks of nine trials are shown in Fig. 3. As may be observed, the introduction of delay in G1 produced an immediate decline in both Al start and running speeds. Analyses of variance over the five blocks of test trials indicated that delay significantly disrupted start speeds $(F=5.90, \mathrm{df}=1 / 78$, $\mathrm{p}<.05)$ and running speeds $(\mathrm{F}=62.62$, $\mathrm{df}=1 / 78, \mathrm{p}<.01)$. The $\mathrm{G} 1$ reward magnitude variable was significant in both start and running speeds $(F=13.41,14.78$, respectively, $\mathrm{df}=1 / 78, \mathrm{p}<.01)$. None of the other interactions were significant.

Alley 2. Mean A2 start and running speeds over blocks of nine trials are given in Fig. 4. With the exception of the start speeds for groups receiving two pellets in $\mathrm{Gl}$, all no-delay groups showed superior performance to that of the delayed groups. Analyses of variance performed over the five blocks of postshift trials indicated that the effect of $\mathrm{G} 1$ reward was statistically reliable for start speeds $(\mathrm{F}=17.64, \mathrm{df}=1 / 78$, $p<.01)$ and running speeds $(F=9.14$, $\mathrm{df}=1 / 78, \mathrm{p}<.01)$. The $\mathrm{G} 2$ reward magnitude variable was not significant for either the start or running measures (Fs $<1$, $\mathrm{df}=1 / 78$ ). Delay of $\mathrm{Gl}$ reward did not reliably affect start speeds $(F<1$, $\mathrm{df}=1 / 78)$, but did significantly reduce run speeds $(F=4.85$, df $=1 / 78, p<.05)$. The G1 by G2 Reward Magnitude interaction was significant for both start and run measures $(F=6.25,4.85$, respectively, $\mathrm{df}=1 / 78, p<.05)$. None of the other interactions were significant.

\section{DISCUSSION}

The present data lend support to the notion that as a consequence of the similarity in operations, the double alleyway should yield behavioral phenomena which resemble those obtained under differential conditioning situations with contrasting reward magnitudes. The major finding which related to the "depression" effect was the slower preshift Al running speeds of Group 2-8 relative to Group 2-2. An "elation" effect, i.e., faster Al speeds for Group 8-2 relative to Group 8-8, failed to occur. The results are seemingly in agreement with the literature in differential conditioning and in particular with an experiment by Matsumoto reported by Black (1968). With contrasting rewards in two separate alley ways, Matsumoto was able to obtain a "depression" effect but not an "elation" effect. The A2 results were not amenable to a contrast interpretation since it may also be claimed that "elation" or "depression" effects could be obtained on the basis of demotivation due to G1 reward (Seward, Pereboom, Butler, \& Jones, 1957).

The effects of constant delay of $\mathrm{Gl}$ reward on $A 2$ performance do not support Amsel's (1958) implication that delay of G1 reward may be interpreted as a frustrative event. To this end, it would be expected that A2 performance should be facilitated by the shift to delay of $\mathrm{G} 1$ reward. The present data confirm results reported by McHose (1966) who found that in a within-S design, delay of G1 solid food reward did not enhance A2 performance. Within the Amsel theoretical framework, it might be expected that a shift to a constant G1 delay would create an interference of previously conditioned anticipatory goal responses $\left(r_{g}\right)$ with delay-engendered conditioned an ticipatory frustration responses $\left(r_{g}\right)$ in Al. In Fig. 3, the rapid decline of $\mathrm{A} 1$ speeds upon shift to delay would seem to support this contention. Amsel (1958) has assumed that enhanced $A 2$ performance due to frustrative nonreward in $G 1$ is contingent upon the strength of the conditioned $r_{g}$ in $A l$. It might therefore be expected that as a consequence of its rather immediate decremental effects on Al performance, a sudden shift to constant delay of $G 1$ reward would not result in facilitated A2 performance.

\section{REFERENCES}

AMSEL, A. The role of frustrative nonreward in noncontinuous reward situations. Psy chological Bulletin, 1958, 55, 102-119.

BLACK, R. W. Shifts in magnitude of reward and contrast effects in instrumental and selective learning: A reinterpretation. Psychological Review, 1968, 75, 114-126.

BOWER, G. H. A contrast effect in differential conditioning. Journal of Experimental Psychology, 1961, 62, 196-199.

DALY, H. B. Excitatory and inhibitory effects of complete and incomplete reward reduction in the double runway. Joumal of Experimental Psychology, 1968, 76, 430-438.

McHOSE, J. H. Delay increase and subsequent responding. Psychonomic Science, 1966, 5, 213-214.

SEWARD, J. P., PEREBOOM, A.C., BUTLER, B., \& JONES, R. B. The role of prefeeding in an apparent frustration effect. Journal of Experimental Psychology, 1957, 54, 445-550.

\title{
The magnitude of the frustration effect as a function of the number of previously reinforced trials'
}

\section{THERON STIMMEL and PHILLIP C ADAMS, University of Houston, Houston, Tex. 77004}

Responding in a double runway following the cessation of reinforcement in the first goalbox was studied as a function of either 35 or 75 prior reinforcements in the first goalbox. Second runway speeds showed a greater increase for the 75-reinforcement group. Results were discussed in terms of frustration theory.

A common, if not universal, finding in the animal learning literature is a nonmonotic relationship between number of reinforced trials and subsequent resistance to extinction. Both North \& Stimmel (1960) and Birch (1961) have employed Amsel's (1958) concept of frustration to account for this nonmonotonicity. According to Amsel, $\mathrm{r}_{\mathrm{f}} \mathrm{s}_{\mathrm{f}}$ (frustration) varies as a function of the level of $r_{g}-s_{g}$. Birch (1961) hypothesizes that at high levels of $r_{g}-s_{g}$ cessation of reinforcement leads to the elicitation of $\mathrm{I}_{\mathrm{f}}-\mathrm{s}_{\mathrm{f}}$ of sufficient magnitude to cause emotional responses incompatible with instrumental responding. This formulation, of course, 


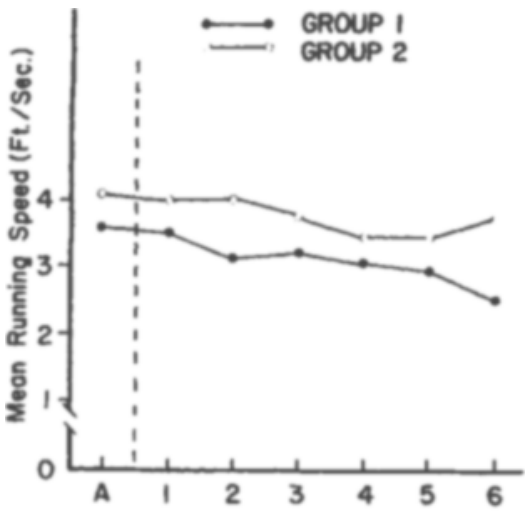

Blocks of 5 Triols

Fig. 1. Mean running speeds, Runway 1 , during last day of reinforcement and 6 days of nonreinforcement in Goalbox 1.

supposes that the magnitude of $\mathbf{r}_{f}-s_{f}$ increases as a function of the number of reinforced trials. The present study investigates this question with a double runway situation.

\section{SUBJECTS}

The Ss were 20 male albino rats of the Cheek-Houston strain which were 300 days old at the beginning of training. The Ss were individually caged.

\section{APPARATUS}

The apparatus was a double, straight-alley runway to be described more fully in a subsequent report. The experiment was conducted in a highly sound-resistant room with dim overhead lights.

\section{PROCEDURE}

Pretraining consisted of 14 days of 1-min per day handling of each $S$. Following handling the Ss were allowed $1 \mathrm{~h}$ of ad lib feeding on Wayne Lab Chow. The amount of food was gradually reduced from $20.22 \mathrm{~g}$ to $15-17 \mathrm{~g}$. The latter amount was given the Ss for $1 \mathrm{~h}$ throughout the remainder of the experiment. Next, the Ss were given 5 days of introduction to the runway. On Days 1 and 2 , the Ss were allowed $3 \mathrm{~min}$ of free exploration of the runway with the photoelectric cells on and all doors open. On the third, fourth, and fifth days the retrace doors and the door into the second runway were closed after the $S$ had passed through them. On Days 4 and 5 , six Noyes $45-\mathrm{mg}$ pellets were available in Goalbox 1 (GB1) and four pellets were available in GB2. The same amount of reinforcement was used throughout training.

Following pretraining the Ss were randomly divided into two groups of 10 each. G1 received 35 trials with reinforcement in GB1 and 30 trials with no reinforcement in GB1 (NRGB1) but reinforcement continued in GB2. G2 received 75 trials with reinforcement in $\mathrm{GB} 1$ and 30 NRGB 1 trials. Ss had five trials per day with an approximately 8-min ITI throughout the experiment. A trial consisted of placing the $S$ into Runway 1 breaking a photoelectric beam. When the $S$ entered GB1 it was allowed $15 \mathrm{sec}$ in the area. Following this the door to Runway 2 opened activating a clock which was stopped by $S$ cutting a photoelectric beam $1 \mathrm{ft}$ into Runway 2. The $\mathrm{S}$ was also confined in GB2 for $15 \mathrm{sec}$. Start, running, and goal latencies were obtained in both runways. At the completion of a daily trial session, the Ss were retumed to their home cages and allowed 1-h access to the lab chow. Water was available at all times throughout the experiment.

\section{RESULTS}

One $S$ in Group 2 was injured during the experiment and was discarded. Figures 1 and 2 represent the mean running speeds for the last day of reinforcement in GB1 (A) and the NRGB 1 days for Runway 1 and Runway 2, respectively. Analysis of variance for running speeds in Runway 1 yield a significant between-groups effect $(F=8.07$, $\mathrm{df}=1 / 17, \mathrm{p}<.025)$, a significant betweentrials effect $(F=15.19, \quad d f=4 / 68$, $p<.001$ ), and a significant Trial by Group interaction $(F=36.65, \mathrm{df}=4 / 68$, $\mathrm{p}<, 001)$. The differences appeared to be due to the fact that Group 1 ran progressively faster across the five trials while Group 2 remained relatively stable across the trials. For the last day of acquisition in Runway 2 , the betweengroups effect was not significant $(F=2.46$, df $=1 / 17, \quad p>10$ ), the between-trials effect was not significant ( $F=2.19$, $\mathrm{df}=4 / 68, \mathrm{p}>.05<.10$ ), while the Trials by Group interaction was significant $(F=2.79, \quad$ df $=4 / 68, \quad p<.05>.025)$. Again, the significant interaction appeared to be due to the fact that $G 1$ increased in speed within the day while G2 did not.

Following the shift to NRGB 1, analysis of variance for running speeds, Runway 1, yielded a significant between-groups effect $(F=5.46, d f=1 / 17, p<.05)$, a significant between-trials effect $(F=48.58$, $\mathrm{df}=29 / 493, \mathrm{p}<.001$ ), and a significant Trial by Group interaction $(\mathrm{F}=1.82$, df $=29 / 493, p<.01)$. A similar analy sis for NRGB 1, Runway 2, yields a significant between-groups effect $(F=7.52, \mathrm{df}=1 / 17$, $p<.025$ ), a significant between-trials effect $(F=4.05, \mathrm{df}=29 / 493, \mathrm{p}<.001)$, and $a$ significant Trials by Group interaction $(F=1.57, \mathrm{df}=29 / 493, \mathrm{p}<.05)$.

\section{DISCUSSION}

The between-group differences observed during NRGBl in Runway 1 can be best attributed to preexisting group differences. Both groups showed a decline in running speed with $\mathrm{G} 1$ declining at a slightly faster rate. To the extent that Runway 1 speed

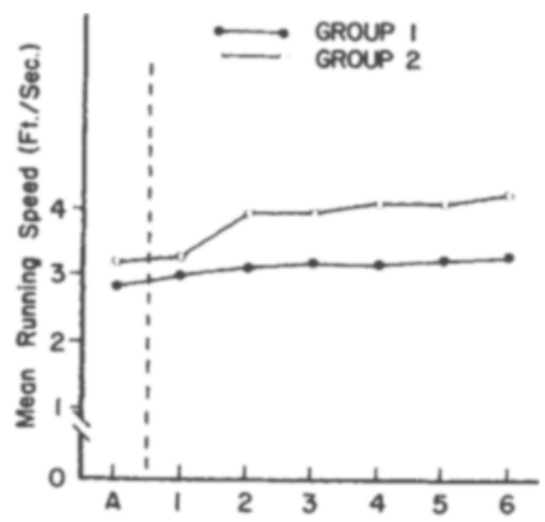

Blocks of 5 Trials

Fig. 2. Mean running speeds, Runway 2, during last day of reinforcement and $\mathbf{6}$ days of nonreinforcement, in Goalbox 1.

decrements are analagous to the usual runway extinction data, the more highly trained group (G2) extinguished at a slower rate. The Runway 2 NRGB 1 data demonstrate an increased speed of running following cessation of reinforcement for both groups with a relatively greater increase for Group 2. While a concept of "demotivation" (e.g., Barrett et al, 1965) might explain the increased speed of running during NRGB 1 for both groups, it is difficult to see why a group with a larger number of reinforcements should show a differential increase in Runway 2 speeds if the amount of reinforcement in GB1 were the determiner of the increased speed. Although, in general, the Runway 2 results might be interpreted as supporting frustration the most dramatic break between Groups 1 and 2 occurred after five trials of NRGB1 and not immediately after the beginning of NRGB 1; and (2) the fact that the differences between the groups increased sharply between Trials 5 and 10 and then remained fairly constant through Trial 30 of NRGB1. One might expect $\mathrm{I}_{\mathrm{f}}-\mathrm{s}_{\mathrm{f}}$ to habituate if that was what was responsible for the difference in the two groups.

\section{REFERENCES}

BARRETT, R. J., PEYSER, C. S., \& McHOSE, J. H. Effects of complete and incomplete reward reduction on a subsequent response. Psychonomic Science, 1965, 3, 277-278.

BIRCH, D. A motivational interpretation of extinction. In M. R, Jones (Ed.), Nebraska symposium on motivation 1961. Lincoln: University of Nebraska Press, 1961 Pp. 179-197.

NORTH, A. S., \& STIMMEL, D. T. Extinction of an instrumental response following a large number of reinforcements. Psychological Reports, 1960, 6, 227-234.

NOTE

1. This study was supported by Grant No. MH 13387-01 from the National Institu te of Mental Health to the first author. 